\title{
Complex magnetic structures in frustrated A-site manganites
}

\author{
E. Solana-Madruga ${ }^{1}$ \\ ${ }^{1}$ CNRS, Université de Lille, Unité de Catalyse et chimie du Solid, 59652 Villeneuve d'Ascq Cedex, France. \\ elena.solanamadruga@univ-lille.fr
}

\begin{abstract}
$\mathrm{ABO}_{3}$ oxides have proven to accommodate a wide variety of chemical compositions, to crystallise with several structures in competition and to develop diverse physical properties. Hence, they are intensively studied in the search for new functional materials. Among them, the use of high-pressure and high-temperature synthesis techniques allows the stabilisation of the small $\mathrm{Mn}^{2+}$ cation in the larger A site. Some of the most exciting A-site manganites are spintronic (e.g. perovskite $\mathrm{MnVO}_{3}$-II) or multiferroic (e.g. $\mathrm{LiNbO}_{3}-$ type $\mathrm{MnTiO}_{3}-\mathrm{II}$ ) [1,2]. Mixing different cations into the A and/or B sites induces cation order and further magnetic complexity. Recent studies on high pressure $\mathrm{Mn}_{2} \mathrm{BB}^{\prime} \mathrm{O}_{6}$ compounds have evidenced the accessibility to new structural derivatives, such as the double double perovskite structures (DDPv) or triple perovskites (TPv) with 1:2 order of the B-site cations $[3,4]$. The possibility to tune both structure and properties as a function of the chemical composition has also been observed, for instance in the $\mathrm{Mn}_{3-\mathrm{x}} \mathrm{Co}_{\mathrm{x}} \mathrm{TeO}_{6} \mathrm{double}$ perovskite $-\mathrm{Ni}_{3} \mathrm{TeO}_{6}$-type solid solutions [5].
\end{abstract}

Here we present a revision on the strongly frustrated magnetic structures of A-site manganites with ordered corundum or perovskite derivative structures (Fig.1). Among the corundum derivatives, magnetic frustration arises as a consequence of the stacking of honeycomb and/or triangular magnetic sublattices. In the case of the perovskite superstructures, it is usually the competition between several magnetic interactions and the combination of $\mathrm{d}^{\mathrm{n}}$ with $\mathrm{d}^{0} / \mathrm{d}^{10}$ cations what induces large frustration indexes. As a result of such frustration both types of polymorphs develop complex magnetic structures, including incommensurate helices, temperature dependent propagation vectors, elliptical and sinusoidal modulation of the magnetic moments, lock-in spin transitions and split of the main magnetic phase into coexisting ground states.
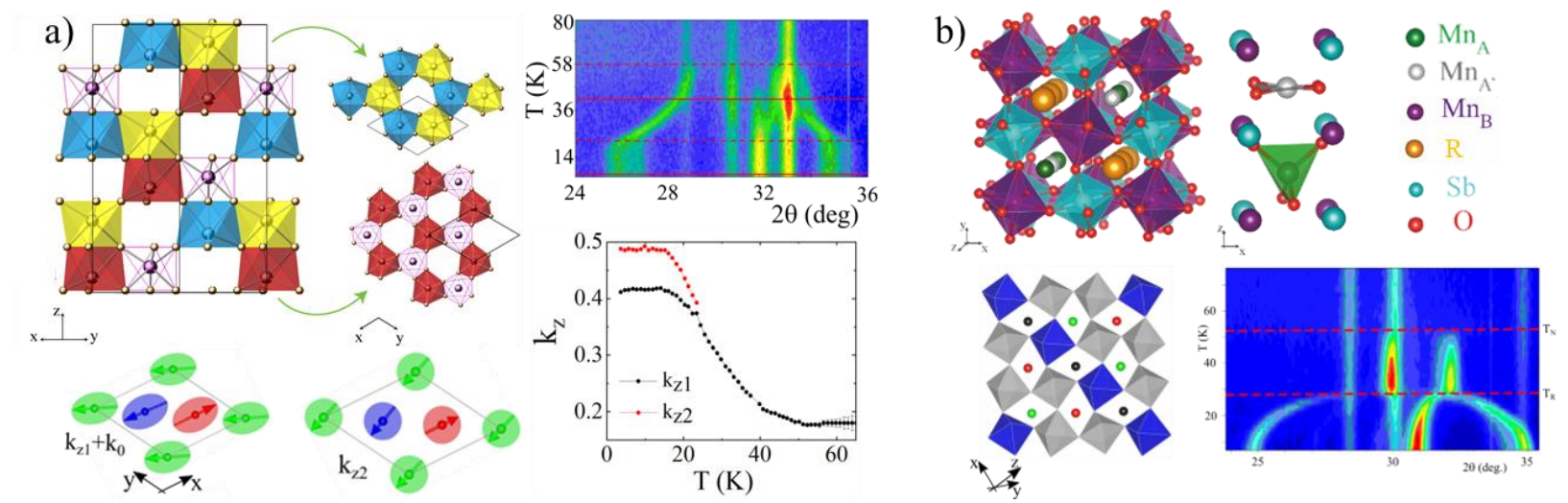

Figure 1. Representative examples of cation order and magnetic frustration in corundum (a) and perovskite (b) derivatives in high pressure A-site manganites. a) Stacked honeycomb/ triangular sublattices (top left), temperature dependence of the propagation vector in $\mathrm{Co}_{3} \mathrm{TeO}_{6}$ (right) with split into circular and elliptical helices (bottom left). b) DDPv and 1:2 TPv structures of $\mathrm{MnRMnSbO}_{6}$ and $\mathrm{Mn}_{3} \mathrm{MnNb}_{2} \mathrm{O}_{9}$ respectively with several magnetic interactions in competition. Complex thermodiffraction of $\mathrm{Mn}_{3} \mathrm{MnNb}_{2} \mathrm{O}_{9}$ developing a SDW modulated structure and lock-in transition at low temperatures.

[1] Markkula, M., Arevalo-Lopez, A. M, Kusmartseva, A., Rodgers, J. A. Ritter, C., Wu, H. \& Attfield J.P. (2011) Phys. Rev. B. 84, 094450.

[2] Arevalo-Lopez, A. M. \& Attfield, J. P. (2013) Phys. Rev. B. 88, 104416.

[3] Solana-Madruga, E., Arévalo-López, A. M., Dos Santos-García, A. J., Urones-Garrote, E., Ávila-Brande, D., Sáez-Puche, R. \& Attfield, J. P. (2016) Angew. Chem. Int. Ed. 55, 9340.

[4] Solana-Madruga, E., Aguilar-Maldonado, C., Ritter, C., Mentré, O., Attfield, J. P. \& Arevalo-Lopez, A. M. (2021) Angew. Chem. Int. Ed. Under revision.

[5] Solana-Madruga, E., Aguilar-Maldonado, C., Ritter, C., Huvé, M., Mentré, O., Attfield, J. P. \& Arevalo-Lopez, A. M. (2021) Chem. Commun. 57, 2511-2514.

Keywords: High pressure; A-site manganites; magnetic frustration

Acta Cryst. (2021), A77, C402 